\title{
An Unusual Case of Delirium after Restarting Clozapine
}

\author{
Sourav Khanra1, Rati Ranjan Sethy ${ }^{2}$, Sanjay Kumar Munda ${ }^{3}$, Christoday Raja Jayant Khess ${ }^{3}$ \\ ${ }^{1}$ Department of Psychiatry, ICARE Institute of Medical Sciences and Research, Haldia, ${ }^{2}$ Department of Psychiatry, Institute of Medical \\ Sciences \& SUM Hospital, Bhubaneswar, ${ }^{3}$ Department of Psychiatry, Central Institute of Psychiatry, Ranchi, India
}

\begin{abstract}
Clozapine is a gold standard medication and drug of choice in refractory schizophrenia. Among many of its fatal side effects, delirium is less reported and inconsistently recognized by clinicians. We here present a case of delirium which emerged during retreatment with clozapine in a patient of paranoid schizophrenia. A patient diagnosed with paranoid schizophrenia, was restarted on clozapine after he left medications and became symptomatic. He was delirious on 22nd day after clozapine was restarted. Clozapine was stopped and the patient was managed with standard treatment for delirium. After one week interval, clozapine was restarted. Delirium was not noted till 6 weeks of his hospital stay. Clozapine induced central anticholinergic toxicity or clozapine induced seizure might cause delirium in index case. Limited literature exist delirium with clozapine. Clinicians must have high index of suspicion to detect delirium during clozapine therapy. More researches should focus to explore the association between delirium and clozapine.
\end{abstract}

KEY WORDS: Clozapine; Delirium; Risk factors; Schizophrenia, paranoid; Retreatment.

\section{INTRODUCTION}

Clozapine is preferred over other traditional antipsychotics and remains 'gold standard' in the treatment of refractory schizophrenia. ${ }^{1,2)}$ Although its other hematological, metabolic and neurological side effects are well known, delirium is less reported and inconsistently recognized. ${ }^{1,3)}$ Delirium can occur upto $10 \%$ of patients treated with clozapine. ${ }^{4,5)}$ A MEDLINE and ScienceDirect review through April 2015 identified only one original article on incidence and risk factors of delirium during clozapine treatment. ${ }^{5)}$ We here present a case of paranoid schizophrenia who developed delirium after clozapine was restarted.

\section{CASE}

A 32 years old male hailing from rural area of Jharkhand, India presented with 10 years history of episodic illness characterized by aggressive behaviors, suspiciousness and impairment of occupational functioning. On mental

\footnotetext{
Received: April 15, 2015 / Revised: July 2, 2015

Accepted: July 27, 2015

Address for correspondence: Sourav Khanra, MD

Department of Psychiatry, ICARE Institute of Medical Sciences \&

Research, Haldia 721645, India

Tel: +91-03224-269262, Fax: +91-03224-269261

E-mail: souravpsy@gmail.com
}

state examination (MSE) he was found to be having delusion of persecution, delusion of grandiosity, second person auditory hallucination. A diagnosis of paranoid schizophrenia was made according to International Classification of Disease 10th version by World Health Organization. Treatment history revealed adequate trials of oral risperidone and haloperidol without acceptable improvement which led trial of clozapine in past. He was maintaining symptom free with oral clozapine $250 \mathrm{mg}$ /day for last 4 years till 3 months back before index visit while he left taking medication and became symptomatic. He was restarted oral clozapine considering past good response. Physical examination and baseline laboratory investigations including complete blood counts, liver function tests, electrocardiography (ECG) were within physiological range. Clozapine was restarted orally with initially $25 \mathrm{mg} /$ day (day 1 through day 3) and titrated $25 \mathrm{mg}$ every 3 days until it reached $100 \mathrm{mg} /$ day. Subsequently, clozapine dosage was increased $50 \mathrm{mg}$ every 3 days until it reached $250 \mathrm{mg} /$ day. While he maintained well for 3 days, in the evening on following day (22nd day after clozapine was started), he was found to be confused, agitated, answering questions inappropriately. Physical examination was unremarkable except tachycardia (120 bpm). MSE revealed disorientation to time and place, difficulty in simple comprehension and impaired recent memory. Rest of

(c) This is an Open-Access article distributed under the terms of the Creative Commons Attribution Non-Commercial License (http://creativecommons.org/licenses/by-nc/4.0) which permits unrestricted non-commercial use, distribution, and reproduction in any medium, provided the original work is properly cited. 
MSE could not be carried out. A working diagnosis of delirium was made and clozapine was stopped immediately. Common causes of delirium in a psychiatric patient including infection, electrolyte imbalance, seizure and drug induced side effects were considered. Because of inpatient stay at hospital, delirium due to withdrawal or intoxication from use of any psychoactive substance was ruled out. Complete blood counts, ECG, serum electrolytes and random blood glucose level were normal. He was managed with intramuscular haloperidol and lorazepam along with supportive measures. Delirium resolved completely on the following day. After one week patient oral clozapine was restarted and gradually titrated up at a rate of $25 \mathrm{mg}$ every 4 days until it reached $200 \mathrm{mg}$. During this period, he did not develop delirium and his psychopathology resolved within 6 weeks of restarting clozapine.

\section{DISCUSSION}

A few reports have documented emergence of delirium associated with use of clozapine. Clozapine alone or in combination with other agents have been observed as a causative factor for delirium. Centorrino et al. ${ }^{5)}$ investigated risk factors for delirium during clozapine treatment. He noted co-treatment with other centrally antimuscarinic agents, poor clinical outcome, older age, and longer hospitalization were associated factors for same. Gender, diagnosis, medical co-morbidity, and daily clozapine dose were unrelated for delirium. Also, delirium was inconsistently recognized clinically in milder cases and was associated with increased length-of-stay and higher costs, and inferior clinical outcome. ${ }^{5)}$ Clozapine, when used adjunctively with electroconvulsive therapy and benzodiazepines, have been reported to produce delirium. ${ }^{6-8)}$ Delirium has been reported after clozapine withdrawal. ${ }^{9-11)}$ Low dose of clozapine as well as a dosage increase of clozapine has been noted to precipitate delirium. ${ }^{3,12)}$ However, only two reports till date have reported delirium after restarting clozapine. ${ }^{13,14)}$ Our case closely resembles this. At a pharmacodynamic level, anticholinergic properties of clozapine and physostigmine reversal of clozapine induced delirium have led central anticholinergic toxicity to be hypothesized as a culprit behind this fatal side effect. ${ }^{12,15,16)}$ This might be one etiology of delirium in index case presented above. Also we could not rule possibility of clozapine induced seizure in our case. Prompt resolution of delirium following discontinuation of clozapine also points toward either of these two possibilities.

Delirium, despite being a fatal but inconsistently recognized side effect of clozapine treatment, has been poorly studied. Clinicians must be cautious during clozapine therapy, irrespective of daily dosage, gender, diagnosis and during both during discontinuation and retreatment phase. Further research to explore pattern of delirium and risk factors for same during clozapine treatment should be conducted.

\section{REFERENCES}

1. Shankar BR. Clozapine-induced delirium. J Neuropsychiatry Clin Neurosci 2008;20:239-240.

2. Kane J, Honigfeld G, Singer J, Meltzer H. Clozapine for the treatment-resistant schizophrenic. A double-blind comparison with chlorpromazine. Arch Gen Psychiatry 1988;45:789-796.

3. Baweja R, Sedky K, Lippmann S. Clozapine associated delirium. East J Med 2010;15:71-72.

4. Gaertner HJ, Fischer E, Hoss J. Side effects of clozapine. Psychopharmacology (Berl) 1989;99 Suppl:S97-S100.

5. Centorrino F, Albert MJ, Drago-Ferrante G, Koukopoulos AE, Berry JM, Baldessarini RJ. Delirium during clozapine treatment: incidence and associated risk factors. Pharmacopsychiatry 2003;36:156-160.

6. Kumar S, Goswami U, Behera D, Khastgir U. ECT and Clozapine combination producing delirium : A Case Report. Indian J Psychiatry 2003;45:193.

7. Manjunatha N, Ram Kumar GS, Vidyendaran R, Muralidharan K, John JP. Delayed onset, protracted delirium and aspiration pneumonitis associated with a combination of clozapine and electroconvulsive therapy. Indian J Psychol Med 2011; 33:80-82.

8. Jackson CW, Markowitz JS, Brewerton TD. Delirium associated with clozapine and benzodiazepine combinations. Ann Clin Psychiatry 1995;7:139-141.

9. Stanilla JK, de Leon J, Simpson GM. Clozapine withdrawal resulting in delirium with psychosis: a report of three cases. J Clin Psychiatry 1997;58:252-255.

10. Iqbal MM, Rahman A, Husain Z, Mahmud SZ, Ryan WG, Feldman JM. Clozapine: a clinical review of adverse effects and management. Ann Clin Psychiatry 2003;15:33-48.

11. Wong OF, Fung HT, Lam TSK. An unusual cause of delirium in a psychiatric patient: abrupt clozapine discontinuation. Hong Kong J Emerg Med 2010;17:163-167.

12. Wilkins-Ho M, Hollander Y. Toxic delirium with low-dose clozapine. Can J Psychiatry 1997;42:429-430.

13. Szymanski S, Jody D, Leipzig R, Masiar S, Lieberman J. Anticholinergic delirium caused by retreatment with clozapine. Am J Psychiatry 1991;148:1752.

14. Benckhuijsen JA, Keet IP. [Delirium on re-starting clozapine after a short break in treatment]. Tijdschr Psychiatr 2007; 49:661-665. Dutch.

15. Schuster P, Gabriel E, Küfferle B, Karobath M. Letter: Reversal by physostigmine of clozapine-induced delirium. Lancet 1976;1:37-38.

16. Schuster P, Gabriel E, Küfferle B, Strobl G, Karobath M. Reversal by physostigmine of clozapine-induced delirium. Clin Toxicol 1977;10:437-441. 